\title{
Drumming the Future: Vietnamese Drumming as a Bridge Between Tradition and Popular Entertainment ${ }^{*}$
}

\author{
Janys Hayes \\ University of Wollongong, New South Wales, Australia
}

\begin{abstract}
The fascination of Vietnamese with drums and drumming reaches back into the pre-historic when bronze drums (Dong Son), from the Red River Delta region of Vietnam's north, were prized trading commodities throughout the Asian world of that time. Now in the 21st century the Dong Son and other historically renowned drum types have become symbols for Vietnam's emergence into an international cultural and economic arena. This paper charts three Vietnamese international events that illustrate the emblematic use of traditional drumming as a nationalistic symbol of modern Vietnam: The Third Asian Indoor Games held in Hanoi in 2009 opened with a drumming spectacle using battle drums; the Jubilee celebrations of the Vietnamese Catholic Church in 2010, opened in the north in the Ha Nam province with an immense traditional drumming performance within its religious setting; the 2012 Hue International Arts Festival incorporated "Resounding the Vietnamese Spirit”, a specific drums and percussion festival, with performances using Binh Dinh war drums, royal drums from Hue, Dong Son drums, and Tay Son battle drums. These displays of traditional drumming it is argued have popularised particular nationalistic styles of drumming amongst Vietnamese youth, extending from the use of drumming in lion dance performances to the emergence of small, youth drumming groups who perform in the streets of Hanoi and Ho Chi Minh City.
\end{abstract}

Keywords: Vietnamese drumming, Hue Festival, popular entertainment, doi moi, ritual drumming, Vietnamese national identity, Vietnamese cultural traditions

\section{Introduction}

This paper argues that the performance of traditional drumming, through its association with rituals from Vietnam's past, is now used emblematically in major Vietnamese international events as a symbolic marker for a growing Vietnamese national identity. The re-emergence of popular interest in ritualised tradition has allowed the current Vietnamese government to use mediatised international events as sites of nation building, through fostering associations with Vietnam's cultural mythology. Charting the ritual significance of drumming and the impacts of colonisation on forms of drumming, it is argued that drumming as a performative practice has associated meanings which remain subliminal and yet significant when used in government organised mega-spectacles. These spectacles have in turn influenced popular entertainment. Before embarking on a discussion of Vietnamese drumming as an emergent form of popular entertainment in Vietnam, this paper begins

\footnotetext{
* Acknowlegements: The paper has presented at International Federation for Theater Research 2013 Annual Conference in Barcelona.

Janys Hayes, Ph.D., lecturer, Faculty of Law, Humanities and the Arts, University of Wollongong.
} 
with a short overview of contemporary Vietnamese cultural politics in order to contextualise concepts of popular culture in Vietnam.

\section{Cultural Politics}

Over the past 10 years, Vietnam has been among the faster growing economies in the world. With a population of over 86 million, Vietnam also has $44 \%$ of its population less than 25 years old. The economic heart of the country lies in Ho Chi Minh City, previously Saigon but renamed in 1976, a year after the Socialist Republic of Vietnam was first formed. The economic “open door” or doi moi reforms of Vietnam in 1986 led not only to a socialist-orientated market economy but also to a radical influx of previously excluded contemporary culture from the west and from China (Diamond, 1997). The aim of doi moi, which translates as "renovation", was to establish an economy where the Communist Party of Vietnam maintained overall control of the economy and key industries, whilst allowing collectives or private ownership of farms and certain factories. The policy also encouraged foreign investment in order to stimulate economic growth. From the early 1990s videos from Hong Kong, Taiwan, Singapore, and the USA flooded the country effecting, not only the locally growing video, television and film industry, but also impacting on the popularity of differing styles of traditional performance. ${ }^{1}$ Young people in particular began to embrace the new types of music, dance and drama entering the country. They also began to abandon Vietnamese performance traditions that had been held in place for centuries.

The dichotomy of these closed and then open processes, economic, social and political, to the influence of external forces, is still resonating in Vietnam today. Variations in the uptake or resistance to change exist across the boundaries of rural populations in comparison to urban populations, northern in comparison to southern and elderly in comparison to youth populations.

In 1998, Resolution five of the Eighth Party Congress of the Party Central Committee identified a need for the return to traditional values and the maintenance of the traditional performing arts, in response to the overriding concern that traditions were being eroded too rapidly and with this the loss of cultural values (Nguyen, 2011, pp. 199-221). ${ }^{2}$ Titled as "Building and Developing a Progressive Vietnamese Culture Rich in National Heritage" the policy of Resolution five has resulted in the reclaiming, preservation, and development of all traditional arts, referring to them as "important intangible heritage".

Both the 1998 Resolution along with doi moi have impacted substantially on cultural directions. However, the means through which culture is filtered within the Socialist Republic of Vietnam is less obvious to the outside observer.

The Communist Party relies on a wide range of mass organisations, which initiate and screen compliance to the Party's policies, a two-way information flow through authorised channels. ${ }^{3}$ Government based artistic committees review all proposed and produced plays. Television programmes, and films from pre-production through to broadcasting are subject to scrutiny by committees. Even with the move away from the state-run

\footnotetext{
${ }^{1}$ Numerous Asian studies scholars refer to the decline of traditional performance forms due to the influx of Western mass media. See Davies, 2006, pp. 314-341; Hansen, 1992, p. 2.

2 Where the effects of the 1998 Resolution five on Hat Boi theatre are examined

${ }^{3}$ Lockhart (1997) charts the modes by which a national network of mass organisations in post 1990s Vietnam has enabled a centralist government to resist the development of political and cultural pluralism despite the opening of the economy to market forces (p. 174). Fforde (2012) asserts that even in 2011 Vietnamese families must deal with state officials regarding, health, education, business etc. on a daily basis (p. 178).
} 
monopoly on film studios that existed until 2002, Communist Party censors still control the final cut of any movie that will be shown in cinemas and performances are controlled through the issuing or non-issuing of permits. ${ }^{4}$ Previewing performances of all plays before a board of censors is necessary to allow for instigated changes. The extent of government manipulation in all cultural events is a reflection of the centralism that still abides with the Communist Party’s overarching power.

This short introduction aims to set the scene for the investigation of the use of traditional Vietnamese drumming as an iconic performative device to enhance nationalistic and cohesive atmospheres at recent Vietnamese international events.

\section{Drums and Ritual}

The fascination of Vietnamese with drums and drumming reaches back into the pre-historic when bronze drums (Dong Son), from the Red River Delta region of Vietnam's north, were prized trading commodities throughout the Asian world of that time. Substantial archaeological evidence from the Dong Son culture (1st millennium BCE—2nd century CE) indicates that the bronze drums, cast in one piece through the lost-wax technique and often weighing 200 kilograms or more were venerated possessions used as regalia, burial objects and musical instruments for ceremonies and festivals. These drums were decorated with realistic images of birds and boats, with geometrical patterns and three dimensional figures often of frogs, reflecting the social and spiritual life of the Lac Viet, the remote ancestors of the Vietnamese. ${ }^{5}$

Since the Ly dynasty (1009-1225), Vietnamese have incorporated the syncopation of drumming within rituals, both at a village level and court level, governing the daily life of Vietnamese citizens. Rituals were practiced for honouring ancestors, for good harvests, for welcoming in each Lunar New Year, for important anniversaries, and were also a fundamental part of state governance. Drumming was used as a prelude to battles, encouraging warriors with passionate rhythms. As well particular types of drums such as the "praise drum" (trong chau) appear in early literature from the Le dynasty (1400-1700) as an accompaniment to Ca tru, the traditional ensemble music used in rituals and village festivals (Norton, 2005).

Music has exemplified the relationship inherent in these rituals, for as Kenneth DeWoskin, an American anthropologist who specialises in Asian studies states,

The music of both court and street linked the lord and his people. The music of the sacrifice linked grateful descendants to the spirits of their ancestors. The music of the rituals linked the ruler with the powers of heaven. (DeWosken, 1982, p. 30)

Each emperor was regarded as an intermediary with the celestial powers, and the role of music in ritual reflected the harmony between the citizens and their positions within the kingdom and the harmony of the people with the emperor. For instance, the Nam Giao ritual sacrifice, the most important feudal ritual ceremony of the Hue Royal Court, which lasted from the founding of the Nguyen dynasty (1802) into the mid-20th century, began with a procession, held once every three years, which travelled from the Imperial Palace in Hue across the Perfume River to a ritual platform five kilometres away. For the most part, this procession was accompanied by

\footnotetext{
${ }^{4}$ Who discusses the rise of privately funded Vietnamese feature films (Cohen, 2004, pp. 58-60).

${ }^{5}$ For a full review of the archeological debate on the origins of bronze drums, see Han (2004, pp. 7-33).
} 
martial drumming and at intervals gonging. The central moment of the ceremony consisted of the emperor climbing onto the platform and entering a tent to meet the heavenly sky spirits. Offerings were made to intercede for the benefit of the emperor's subjects (Gibbs, 2007).

\section{Impacts of Colonisation}

The impact of colonisation and the subsequent rise of communism altered the cultural significance of all of the traditional modes of music. From the Hue Court to the northern and southern villages, foreign influences changed the balance between tradition ways of life and rituals and the new influences of technology and intervention.

For instance, Jason Gibbs, an American musicologist, specialising in Vietnamese music, examines the intercultural contact between French popular music of the early 20th century and Vietnamese traditional music (Gibbs, 2003). Analysing the beginnings of cai luong performances, which often initially incorporated Western style military bands with military drumming, Gibbs lists two "extramusical factors" (Gibbs, 2003, p. 73) influencing the assimilation processes of this foreign music into the Vietnamese musical repertoire. Firstly, he writes of the prestige factor, where the high status and modernity of the French were perceived as assisting an “escape ... [from].... backwardness” (Gibbs, 2003, p. 74). The foreign musical forms were accepted, altering previous traditional forms because of their links with an elite class. Commercialism is the second factor Gibbs lists in relation to the contact between the two varying forms of music. Emulation of western media resulted in the rising popularity for pre-existing cai luong troupes that nowintegrated Western music including drumming into their performance repertoire. These troupes were more financially successful, even as widespread criticism of the intercultural forms persisted.

Cheo is another form of traditional Vietnamese performance which highlights drumming and which has been influenced by colonisation. Whilst first appearing in the 14th century in the northern delta region of Vietnam as outdoor entertainment for festivals held after the Tet New Year, in the early 20th century cheo became one of the earliest cross-cultural theatrical forms. In cheo narratives, songs and dances are combined in a satiric style, featuring strong female characters, and a clown figure as well as off-stage voices that interact with the onstage characters (Wilcox, 2006). Musicians play a range of instruments including the two-stringed guitar and the two-stringed violin, the flute, the drums, and cymbals. The percussion can extend to the large drum, the little drum, the cylindrical drum, cymbals, and wooden bells. The drums keep the accompaniment and rhythm for the dancing and singing. Through French influences cheo moved from the village setting to a proscenium arch staging, with cosmopolitan costuming. Called "civilised cheo" this form developed scripted narratives moving away from the original totally improvised form (Wilcox, 2006, p. 211). Janaczewska (1994) notes that even before the 1920s, cheo had become a site for revolutionary narratives in response to the threat of colonisation.

Perhaps in a more popular vein, the Lion Dance,a folk art form derived from China, performed at festivals, especially the Lunar New Year and the Mid-Autumn Festival, also has been influenced by "extramusical factors" (Gibbs, 2003, p. 73). The Lion Dance crew usually consists of a person who wears the paper lion's head and dances to reproduce the animal's gestures by the beat of a drum. A second dancer waves along coloured, fabrictail to the dance rhythms. The instruments in the performance include drums, cymbals, and gongs. The Lion Dance drumming is to a fast well-balanced rhythm, and is often beaten by a group of three or more, which 
is combined with beating the barrel of the drum, creating the sharp sounds in the dance. The lion represents prosperity, wealth, and abundance. The styles of the lion masks have altered to suit the visual tastes of each new Vietnamese generation, including this recent generation who has grown up with television. Modern papier-mache masks for instance may display the lion's head with pink eyebrows, orange hair, and red ribbons, or have a lime-green lion-face with cartoon-styled shaggy ears (Tran, 2002).

Only with doi moi and then the later Resolution five of the Eighth Party Congress was a deliberate return to tradition reinstated through government policies. Whilst during the revolutionary period many cultural traditions were condemned by the Communist Party and officials, now certain cultural traditions were promoted. It has been as if past cultural memories are being revised and reimagined in order to construct a Vietnamese national identity, which links past history to the present. In Hue-Tan Ho Tai's 2001 book, The Country of Memory: Remaking the Past in Late Socialist Vietnam, the writer views the resurgence of pre-revolutionary tradition as a means of melding public memory with official history. Reclaiming and revitalising cultural traditions utilise nostalgia to soften criticism of the present. The reminder of a long and culturally significant history can "coexist[s] in a symbiotic fashion” (Tai, 2001, p. 7) with state sanctioned history.

\section{Drumming the Nation}

The process of utilising traditional drumming as an elementin constructing a modern nationalistic identity for Vietnam can be examined through analysing three international Vietnamese events. In each of these three events: the Third Asian Indoors Games opening ceremony in Hanoi in 2009, the opening and closing of the Jubilee celebrations of the Vietnamese Catholic Church in 2010, and the Hue Festival's "Resounding the Vietnamese Spirit” drum festival in 2012, the contemporary event can be viewed as a scripted public event which has been ritualised and mediatised through embodied performative practices. ${ }^{6}$ It is through performance, both by the performer and for the audience that highly emotive bonds of identification are created. The viewers, whether through being present at the events or through a mediatised experience are drawn into a self-representational watching. The events incorporate elements of rituals from past traditions which have been displaced by the present regime but which have now been sanctioned to re-emerge carrying with them resonances of past meaning. As Ho Tai has noted the present is linked to an illustrious past, which then legitimates the current regime.

\section{The Third Asian Indoor Games 2009}

The Third Asian Indoor Games held in Hanoi in 2009 opened with a drumming display (Retrieved from http://www.youtube.com/watch?v=hvDM6jloa8g). Announcing that drums are an indispensible element in Vietnamese culture, the audience were greeted prior to the official speeches with hundreds of drummers, with fluorescently lit drumsticks, beating out a mesmerizing rhythm. The Asian Indoor Games, organised by the Olympic Council of Asia and held specifically for Asian nations attracted 42 competing national teams and was held for the first time in Vietnam with the opening ceremony at the My Dinh National Stadium. Two thousand four hundred and fifty-six athletes competed, 400 of whom were Vietnamese, indicating the size of the event. As with the Olympic ceremonies, the opening ceremony of the Asian Indoor Games offered an opportunity to present the host country's cultural heritage as a distinct identity. In this case, during the ceremony, images of the

\footnotetext{
${ }^{6}$ See Salemink’s (2007) article for a discussion of the means through which Hue Festival ritualizes modern performative events.
} 
classical water puppet figures were waved on high, flag waving which is a traditional Vietnamese skill was presented en masse, Vietnamese folk dancing, with lines of Vietnamese women in au doi filled the arena and hand-held dragons streamed over the heads of lines of performers all as part of a unique image of Vietnamese culture. As Hogan (2003), sociologist and Asian Studies researcher has noted in relation to the opening ceremonies of the Olympics, events such as these become "key sites in the discursive construction of a nation" (pp. 100-123). It is not only international tourists who view such spectacles, the majority of viewers are able to view the events via television, creating an experience of self-watching for the populace from the host country.

In a mode mirroring the opening of the Beijing Olympics in 2008, the Third Asian Indoor Games used the opening drumming spectacle as a means of transfixing the audience with the power of a musical and movement performance. The body gestures including the striking arms with their lit up drumsticks, the voices of the performers and the sound of the drumslink back to their roots in ritual (Lawson, 2011). The boom of the bass drums followed by the rattle and attack of battle drums connected the spectacle to the past and the power of ancient Vietnamese armies. Jilly Traganou, researching the iconography of Olympic opening ceremonies calls the ritualised elements in the opening ceremony performances, “deep structures”, where at a subliminal level audiences are led to a realtionship that has resonances with a sacred sphere (Traganou, 2010, pp. 236-251).

Taylor (2003), writing on the anthropology of contemporary Vietnam, suggests that the embracing of a wide range of ritual practices, as well as traditional cultural practices re-emerging as cultural reference points is being led as much by the urban elite as by the government itself. Urbanisation is occurring at a rapid rate in Vietnam and Taylor suggests that the anxieties of transitioning from a closed, less materialistic and less individualistic society, to an open global society has created a desire by the educated urbanised classes for past cultural iconographies. Drumming through being associated with the rituals of earlier ages, and the signification of a cosmological order embedded in nature can assure an audience that even with change social harmony is possible. By setting the drumming amongst highly developed performance technology the host audience is aware of the international globalised culture that Vietnam is now operating within, whilst the message of unity between the populace and its ruling government is implicit.

\section{Opening Ceremony of the Jubilee Year of the Vietnamese Catholic Church}

The Jubilee Year celebrations of the Vietnamese Catholic Church in 2010, whilst being clearly religious may also be viewed as state sanctioned public events. These celebrations marked the 50th anniversay since the founding of the Catholic heirarchy in Vietnam and the 350th year since Roman Catholicism arrived in Vietnam. Catholicism had been first introduced by the French in the south of the country and had grown in popularity until the fall of Saigon in the Vietnam/American war. Whilst all religion was banned when the Socialist Republic of Vietnam was first formed, since doi moi religious renewal has been encouraged, both organised religion as well as village ancestor ritual (Salemink, 2007). In contemporary Vietnam, every religious body needs official approval from the Government committee on Religious Affairs. However, whilst the Catholic Church's leadership is directed by the Vatican, the parishioners have to belong to the Solidarity Committee of Patriotic Vietnamese Catholics, linking their governance to the supervision of the Vietnamese Communist Party (Hayton, 2011). In effect the Catholic Church is only partially independent from the state. 
The Jubilee Year celebrations in effect began on 23rd November 2009 and lasted until 9th January 2011. The openingceremony was held in the north in the Ha Nam province in So Kien, $70 \mathrm{~km}$ south of Hanoi. More than 100,000 attended, including 30 Vietnamese bishops, 1,200 priests and Catholics from the 26 dioceses across the country as well as Catholic representatives from other countries (Dang, 2009). After the opening Mass, the Festival Opening Night began with an immense traditional drumming performance, along with trumpet sounding, all within a religious setting (Retrieved from http://www.youtube.com/watch?v=EcFqeBKg7x4). This was a new ritualised event, appearing as part festival and separate from the ritual of the mass. Four hundred performers, from the Diocese of Bin Chu drummed, surrounded by a sea of candlelights, followingthe procession of 118 sisters of the St Paul Congregation from Hanoi, who were representing the Catholic martyrs from previous eras of Christian repression.

The presence of the parade of Catholic sisters in this event is one of the "deep structures" that Jillie Traganou has refrred to in relation to ritualisation set within national performances (Traganou, 2010, p. 242). The women parading represented both male and female Christian matryrs, however through their female presence they also hearkened back to the goddess worship rituals that predominated within an earlier Vietnam. These goddesses often served to resist Vietnamese enemies, for instance, The Lady of the Realm, one of the most popular goddesses from the Mekong Delta region, resisted the Khmers and the Thai and was worshipped annually with a festival timed with the moon cycle (Taylor, 2003, p. 392). Through a subliminal association to goddess worship there is a sense in the Catholic ceremony of a reference to a defence of physical security, even a defence of purity that is transmitted to the host audiences. The drumming tradition in this context is linked to ancestor worship, and to the past dead.

This Opening Festival Night was also reported in the state media as an event which served as positive evidence of the effectiveness of the Government's Religious Freedom policy (An Dang, 2009). So although for those who identified with the Catholic church the meaning of this huge event needs to be seen in a religious context, for the majority seeing the publicity, it could also be interpreted as a politically expedient event acting to promote the Vietnamese identity at a national and international level.

The closing ceremony of the Jubilee Year, held at La Vang parish, Hai Lang district in the Quang Tri province on 5 January 2011 made the links between state and religion more apparent. There the Deputy Prime Minister Nguyen Thien Nhan (2011) stated:

This shows the world the concord between religions and the nation in Vietnam. The State of Vietnam always respects and ensures the people's right to freedom of belief and religions. (Retrieved from http://en.vietnamplus.vn/Home/Vietnam-Catholic-Churchs-jubilee-year-2010-closes/20111/15229)

The drumming from the Festival Opening Night may again be viewed as symbolic of Vietnam's emergent international identity, an identity differing from what had existed before doi moi.

\section{Resounding the Vietnamese Spirit Drumming Festival, Hue 2012}

Probably the clearest public and state sanctioned revitalisation of the tradition of drumming occurred in April 2012 at the 2012 Hue Festival. "Resounding the Vietnamese Spirit”, was a specific drums and percussion festival within the Hue Festival which profiled 12 drumming and percussion troupes both from Vietnam as well as other Asian countries. The Hue Festival is one of Vietnam's most popular cultural events. In 2012, it attracted 
$\begin{array}{llllll}\text { close } & \text { to } & \text { million } & \text { visitors } & \text { (Retrieved }\end{array}$ http://english.vietnamnet.vn/en/society/21229/countries-address-lasting-avian-flu-threat.html). “Am Vang Hao Khi Viet" was directed and organised by the Le Quy Duong Company, one of the foremost festival theatre companies in Vietnam and took place at Nghinh Luong Dinh square, by the banks of the Perfume River. Le Quy Duong states in interview that he created the drumming festival at Hue in 2012 particularly to appeal to young people as they comprise over half of the population of Vietnam under 35 (personal communication, November 30, 2011).

Numbers of the drumming events in "Resounding the Spirit of Vietnam" were deliberately traditional. For instance, the Dong Son brass drums performance dates from the Hung Vuong era (2879 B.C.) and relies on the myth of the founding of Vietnam through the magical union of the dragon lord, Lac Long Quan with the mountain fairy, Au Co (Hue, 2012). In legend Au Co gave birth to 100 eggs, 50 sons, and 50 daughters with the eldest son, Huong Vuong moving to the coast, the Red River Delta region of Vietnam and establishing the Hung kings era which lasted for hundreds of centuries. At Hue Festival 2012, the Dong Son drums were flanked by 100 drums representing the children of the mythical anscestors.

Whilst many of the performances at Hue Festival could be regarded as secular, the resonances of “deep structures" at Hue Festival, where ritual borrowings are intertwined with other genres or disciplines create an overarching sense of integrating aesthetics with ritual (Salemink, 2007). The founding myth of the union between fairy and dragon for instance reappears at many of the Hue Festivals embedded in a variety of artistic forms. Drumming is only one performance genre emerging to take on the mantle of the symbolic.

Another traditional drumming performance at Hue Festival 2012 was that of the Tay Son battle drums used originally during a period of offensives against China in the 18th century. Martial artists strengthened the will of soldiers to fight in combat through drumming and martial arts displays. Combative orders were issued via drums. Tay Son Martial Orchestras include war drums, trumpets, xona (also known as squeeze horns), gongs, and pheng la (tambourines). TheTay Son battle drumsbeat in a 12-beat rhythm, representing the zodiac and are classified into three grades of strength of beat, representing three philosophies of God, land, and human (personal communication, November 30, 2011) ${ }^{7}$. The combination of drumming plus martial arts creates a performance that is both dance and music. This ritualised representation of the interconnection of military might with cosmological philosophies is an enabling image, which whilst not explicitly stated offers an association of national power to Vietnam's youth.

In highlighting drumming at the 2012 Hue Festival, directorLe Quy Duong's statedaim was to shift not only the predominant sounds of the festival but also the ways in which the festival is read by audiences. Speaking in an interview with the author he offers that:

Drumming is not political; it can avoid a political forum. Drums can attract many different kinds of people. Different ages, from different parts of Vietnam and it will create a different sound for the Festival. (personal communication, November 30, 2011)

Whilst not overtly political this paper asserts that drumming through its associations with ritual traditions from Vietnam's past history is being utilised, particularly at the Hue Festival as a means of performative political

\footnotetext{
${ }^{7}$ Interview with Le Quy Duong (November 30, 2011), Ho Chi Minh City.
} 
ritual (Salemink, 2007). In avoiding an overtly political message Le Quy Duong revives a ritualised tradition, which lends significance, through emotional identification, to the current regime. Although "Resounding the Vietnamese Spirit" may be viewed as a multinational, cosmopolitan form of popular entertainment, it also functions to contribute to the construction of the nation.

\section{Popularising of Traditional Drumming}

The complexity of new forms of traditional performance, such as drumming, being reinvented or revised to substantiate the building of Vietnam's cultural identity is materialised in the ways in which these re-contextualised forms of drumming then merge with popular culture. Vietnam's major cities now hum with new supermarkets, karaoke saloons, cyber cafes and discos. The traditions bearing the weight of the past are rapidly absorbed and reutilised for commercial means and entertainment by entrepreneurial youth. Drumming troupes, with varying degrees of traditional elements now perform regularly on the streets of Hanoi and Ho Chi Minh City, at the opening of major new shopping complexes, at street festivals, for instance, at Tet New Year celebrations, and as entertainment for night clubs and community events.

These troupes are a hybrid mix of the appearance of traditional drumming troupes with westernised elements, such as pop-band style outfits, extended western style dancing interspersed in the drumming, and video clips to advertise their presence. As new drumming troupes emerge, they are basing their look and their media presence on the higher status of first world mediatised lifestyles. These in turn are influencing the popularity of theseemergent forms. Although Vietnamese newspapers often disparage the contemporary music tastes of youth the popularity of the new-look drumming troupes continues to grow (Gibbs, 2009).

\section{Conclusion}

In this paper, the author has argued that the performance of traditional drumming in major Vietnamese international events contributes to the construction of a national identity through associations to past rituals and myths. Since doi moi, the re-invention of ritualised tradition has created opportunities for the Vietnamese current government to participate in new ritualised performance events that legitimate its authority. Processes of mediatising these events substantiate nation building, allowing Vietnam-wide audiences opportunities to feel connected to the growth of a unified and harmonious Vietnam in a globalised culture. The subliminal messages conveyed by the presence of drumming in these mega-events hinge on the ritualised aestheticsof the performances. The drumming is not necessarily viewed as symbolic, but rather the drumming is a performative practice through which audiences become emotionally identified through their exposure to past meanings of drumming in various rituals. Whilst audiences range in their nationalities, cultures, religions, and economic status, the drumming is an effective mediator of meaning, crossing boundaries through shared links with a range of rituals and performances. The use of traditional drumming, with the recognition of historically specific drum types, also serves to legitimate the present regime through creating a clear lineage from the past history of the country to the present; it creates a narrative of authenticity. Whilst drumming in these state organised, international forums can be viewed as shaping a national identity, the popular forms of drumming arising as a result of elevating the worth of the traditional forms, illustrate the same kind of hybridity seen in previous eras of colonisation. Traditional forms of musical performance have been moulded through "extra musical 
factors”, where attractions to more commercialised forms begin to pervade the traditional. So drumming in Vietnam is appearing in many guises and styles, with media presence a dominating factor in the shaping of each drumming troupe.

\section{References}

An Dang, J. B. (2009, November 23). Dark cloud hovering the grand opening ceremony of Holy Jubilee in Vietnam. Viet Catholic News. Retrieved from http://www.vietcatholic.net/News/Html/73669.htm

Cohen, M. (2004). Private screening. Far Eastern Economic Review, 167(17), 58-60.

Davies, S. (2006). Balinese Legong: Revival or decline? Asian Theatre Journal, 23(2), 314-341.

DeWosken, K. J. (1982). A song for one or two: Music and the concept of art in early China. Ann Arbor, MI: Centre for Chinese Studies. Diamond, C. (1997). The Pandora's Box of "DoiMoi”: The open-door policy and contemporary theatre in Vietnam. New Theatre Quarterly, 13, 372-385. Retrieved from http://journals.cambridge.org/abstract_S0266464X00011532

Fforde, A. (2012). Vietnam in 2011: Questions of domestic sovereignty. Asian Survey, 52, 176-185.

Gibbs, J. (2003). The West's songs, our songs: The introduction and adaptation of Western popular song in Vietnam before 1940. Asian Music, 35(1), 57-83.

Gibbs, J. (2007). The music of the state: Vietnam's quest for a national anthem. Journal of Vietnamese Studies, 2(2), 129-174.

Gibbs, J. (2009). Contemporary Vietnamese music abundant but in disorder. Vietnam News.

Han, X. R. (2004). Who invented the bronze drum? Nationalism, politics, and a Sino-Vietnamese archeological debate of the 1970s and 1980s. Asian Perspectives, 43(1), 7-33.

Hansen, K. (1992). Grounds for play: The Nautanki theatre of North India. Berkley: University of California Press.

Hayton, B. (2011). Vietnam rising dragon. New York and London: Yale University Press.

Hogan, J. (2003). Staging the nation: Gendered and ethnicized discourses of national identity in Olympic opening ceremonies. Journal of Sports and Social Issues, 27(2), 100-123.

Hue Festival wrapped up by a music party (2013). Retrieved from http://english.vietnamnet.vn/en/society/21229/countries-address-lasting-avian-flu-threat.html.

Hue, T. T. (2012). The Drum Festival and Percussion Instruments entitled "The Resounding of the Vietnamese Spirit”. Talk Vietnam. $\quad$ Retrieved from http://talkvietnam.com/2012/04/the-drum-festival-and-percussion-instruments-entitled-the-resounding-of-the-vietnamese-spir it/

Janaczewska, N. (1994). They're dancing the Lambada in Hanoi. Theatre in Southeast Asia: Australasian Drama Studies, 25(2), 158.

Lawson, F. (2011). Music in ritual and ritual in music: A virtual viewer's perceptions about liminality, functionality, and mediatization in the opening ceremony of the 2008 Beijing Olympic games. Asian Music, 42(2), 3-18.

Lockhart, G. (1997). Mass mobilisation in contemporary Vietnam. Asian Studies Review, 21, 174-179.

Nguyen, K. T. (2011). Another midsummer night’s dream in Ho Chi Minh City. Asian Theatre Journal, 38(1), 199-221.

Norton, B. (2005). Singing the Past: Vietnamese Ca Tru, Memory, and Mode. Asian Music, 36(2), 27-56.

Salemink, O. (2007). The emperor's new clothes: Re-fashioning ritual in the Hue Festival. Journal of Southeast Asian Studies, 38(3), 559-582.

Tai, H.-T. H (Ed.). (2001). The country of memory: Remaking the past in late socialist vietnam. Berkley, CA: University of California Press.

Taylor, P. (2003). The Goddess, the ethnologist, the folklorist and the cadre: Situating exegesis of Vietnam's folk religion in time and place. The Australian Journal of Anthropology, 14(3), 383-401.

Traganou, J. (2010). National narratives in the opening and closing ceremonies of the Athens 2004 Olympic Games. Journal of Sport and Social Issues, 34(2), 236-251.

Tran, M. (2002, February 8). The region; one man’s hobby, a culture’s history: Tet: A mask collector turned trouper keeps dragon and lion dancing a living tradition. Los Angeles Times, p. 6.

Vietnam Catholic Church's Jubilee 2010 year closes (2011). VNA News Services. Retrieved from http://en.vietnamplus.vn/Home/Vietnam-Catholic-Churchs-jubilee-year-2010-closes/20111/15229

Wilcox, W. (2006). Women, westernization and the origins of modern Vietnamese theatre. Journal of Southeast Asian Studies, 37(2), 205-224. 